\title{
Oral health project wins innovation award
}

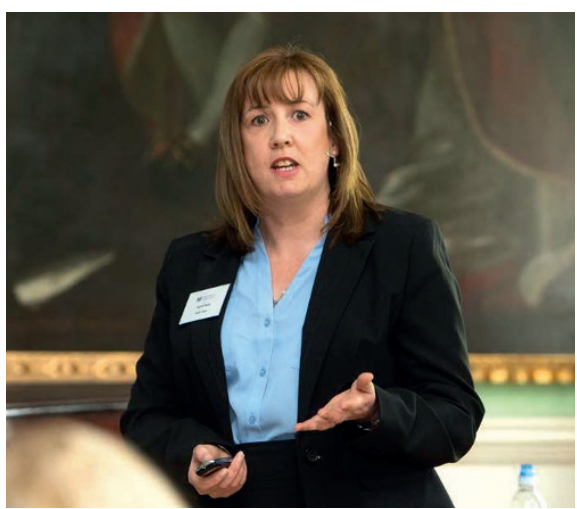

Community-based oral health project Teeth Team is the first winner of the newly-created British Society of Paediatric Dentistry (BSPD) Outstanding Innovation Award.

Teeth Team was set up in 2010 in a deprived area of Hull to initiate tooth-brushing programmes in schools and soon won the support of schools, local dental practices, dental suppliers and politicians. The number of children from the area having a general anaesthetic for multiple extractions has since decreased by nearly $20 \%$ and Teeth Team has played a key role in this.

Project founder and dental practice manager Ingrid Perry (pictured) said: 'In Hull there was a whole generation of families for whom it was normal never to see the dentist except to go to hospital to have teeth extracted. That's all they know. But we got talking to children, broke down the barriers and now families are accessing routine dental care.'

BSPD spokesperson Claire Stevens praised everyone involved in the initiative and said: 'Teeth Team provide the evidence that where there is a commitment to make dental health a priority in schools, change is possible. Children's oral health is everyone's business

\section{Oral health figures are a 'national scandal'}

New analysis by the Faculty of Dental Surgery at the Royal College of Surgeons shows there has been a $24 \%$ rise in the number of tooth extractions performed on $0-4$-year-olds in hospitals in England over the last decade. This is the first time long term data for 0-4-year-olds has been published.

NHS Digital figures, provided under a Freedom of Information request, show there were 84,086 procedures carried out on 0 -4-year-olds between 2006/07 and $2015 / 16$. This is a steep increase when compared to a $16 \%$ increase in the population of 0-4-year-olds over the same period.

Commenting on the figures, the British

Dental Association (BDA) lamented the lack of government strategy and action on tooth decay and England's persistent oral health inequalities over the last decade. Both Scottish and Welsh devolved governments have funded dedicated programmes that have had transformative effects on children's oral health.

The figures also show more than 34,000 tooth extractions were performed on 0-9year-olds in the each of the last two years.

BDA Chair Mick Armstrong said: 'An

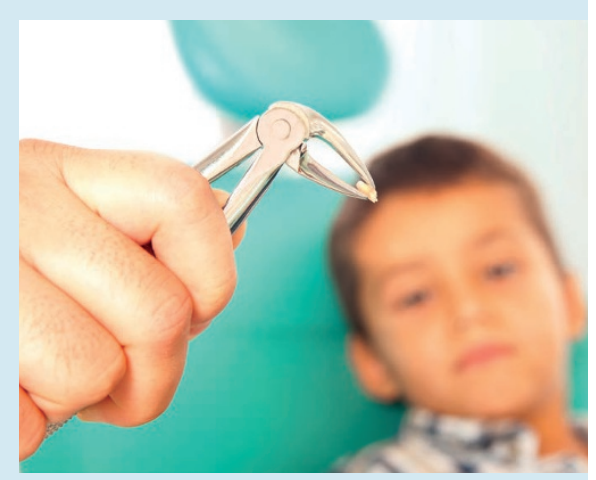

entirely preventable disease is going almost unchallenged as the leading cause of hospital admissions among young children. These extractions are placing a huge strain on the NHS, and while governments in Wales and Scotland have set out dedicated strategies, ministers in England have offered little more than a collective shrug.

'It's a national scandal that a child born in Blackburn is now seven times more likely to experience decay than one born in the Health Secretary's Surrey constituency. These deep inequalities now require real commitment from government, not just token efforts.' and this is a perfect example?

The prize for winning the award is the opportunity to give a presentation at the BSPD conference. As the founder and the secretary, Ingrid has been invited to be a conference speaker.

Dr Stevens praised the other entries to the award, which included:

- A portfolio of resources to help reduce dental anxiety in children from a team at Sheffield University led by Zoe Marshman

- The RISK DISK, a caries risk assessment tool developed by Sophie Marshall and Thayalan Kandiah

- An online oral health and risk assessment tool for young patients called the Young DEPPA (Denplan PreViser Patient Assessment tool) developed by a team led by Stephen Fayle, Iain Chapple, Mike Busby and Liz Chapple.

\section{Appointments}

\section{BDIA Chief Executive}

Edmund Proffitt has been appointed the new Chief Executive of the British Dental Industry Association (BDIA). Edmund is currently Policy and Public Affairs Director and will assume his new role from 10 April.

BDIA Executive Director Tony Reed is stepping down from his position in April, after running the Association for over 20 years. Tony will remain involved with the BDIA in a financial capacity going forward.

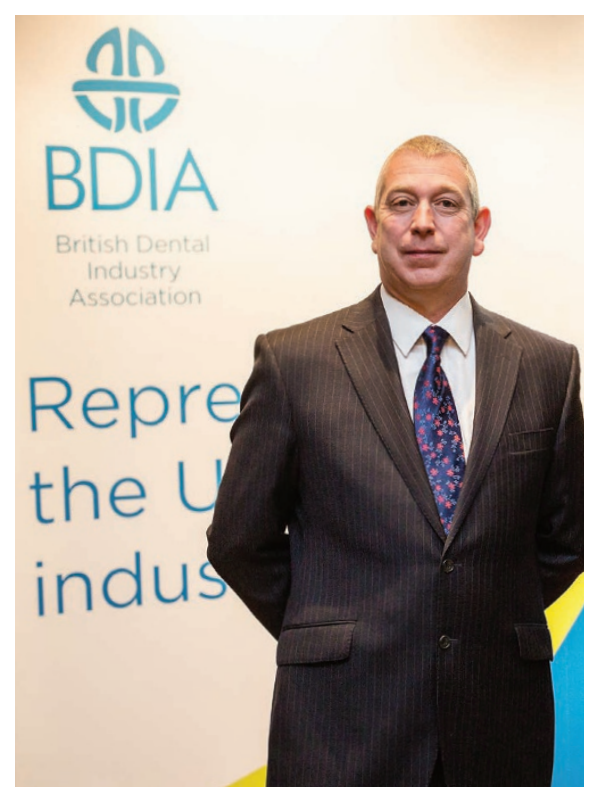

